\title{
THE INFORMATION OVERLOAD PHENOMENON: THE INFLUENCE OF BAD - AND (IR) RELEVANT INFORMATION
}

\author{
Thomas Rachfall ${ }^{1}$, Elizabeth Williamson ${ }^{2}$, Bryan Temple ${ }^{3}$ \\ ${ }^{1}$ Hochschule für Technik und Wirtschaft Berlin, Fachbereich Wirtschaftswissenschaften II, Wilhelminenhofstraße 75 \\ A, 12459 Berlin, Germany \\ ${ }^{2}$ Glasgow Caledonian University, Glasgow School for Business and Society, Glasgow G4 OBA \\ ${ }^{3}$ Glasgow Caledonian University, Glasgow
}

\begin{abstract}
Almost every knowledge worker can relate to feelings of Information Overload (IO), but in reality the phenomenon is not well understood. IO can be critical for individuals and organizations. Despite intensive research during the last decades this complex scientific discipline lacks comprehensive research for parts of the possible impact factors. This research presents a conceptual framework and some variables to the type of information. A case study approach has been conducted to examine the relationship between bad-, irrelevant- and relevant information with IO. The research found out that too much bad information as well as relevant information has a positive effect on IO. The contribution to the field of IO research is a better understanding of the concept and the impact of the type of information to $I O$.
\end{abstract}

Keywords: Information Overload; information processing, bad and irrelevant information

Conference Topic: Information Technology

\section{INTRODUCTION}

The continuous and irresistible progress of economies and technology has created such a turbulent environment that organizations have to react fast to internal and external changes [Doppler/Lauterburg, 2000]. Furthermore the development of information and communication technology and the rise of the knowledge economy have both contributed to the importance and impact of information within business [Bouwman et al. 2005, p.3]. The latest phase of ICT development has resulted in integrated business processes and large databases which may be accessed by a variety of methods and applications [Bouwman et al. 2005, p.4]. The further development of management information systems, such as Enterprise Resource Planning (ERP) systems, Customer Relationship Management (CRM) systems and Supplier Relationship Systems (SRM) make sure that internal information as well as external information is available to many employees in an organization at any time. These have led to the situation of much or even too much information being available for decision making purposes. This is not critical at all, if everybody could filter his specific information [Wingens 2007 , p. 1]. But it gets more difficult to separate relevant from non-relevant information; thereby a paradox accrues: within a flood of information a lack of information exists. This effect influences employees as well as organizations, because valuable information is the basis of good decision making. But the task of choosing the most valuable information is a more challenging task than ever [Baumöl 2008, p. 12]. Katzer [1996, p. 217] for example discovered that $96 \%$ out of 1,996 managers always feel that they do not have enough information to make a decision.

Dryer et al. [1999, p.653] believe that the use of ICT is becoming more pervasive and is associated by users with an increasing amount of information. The inability to escape from ICT and the growing volume of information is recognized as a problem and therefore reflected in the literature [Allen et al. 2005]. In addition, the capacity of the human brain in processing information is limited and many factors make it difficult to filter information. It is not only the quantity of information (such as e-Mail), but also other conditions complicating the filtering process, for example the different information-quality, interruptions and its permanent availability [Dietze 2003, p. 183]. As Peavler [2009, p.559] point out, these IO problems, affect both individuals and organizations. As a consequence of IO, individuals feel stress, loss of job satisfaction and physical ill health [Farhoomand 2002, p. 127 and Kulke 2007, p. 10]. For organizations the effect is also enormous. Intel [Zeldes 2007] predicts that as a consequence of IO every back office employee works unproductively for eight hours per week. To contribute a better understanding of the IO phenomenon this research shows that too much bad information as well as relevant information has an effect on IO.

\section{THEORY}

IO is an often mentioned phenomenon in our globalized society and scientists have analysed the phenomenon since decades. Both quantitative and qualitative research about causes, symptoms and countermeasures has been carried 
out. Eppler and Mengis [2002] as well as Edmunds and Morris [2000] summed up most of the existing work in their literature reviews. This contribution focuses on a specific part of the phenomenon: the type and amount of information which influence the IPR (information processing requirements).

\subsection{Information Overload}

Most people use the term IO and mean that they just get too much information. But the term IO is by far more complex. Several scientific disciplines and circles are researching and discussing IO (among others: psychology, stress science, decision making, biology, accounting, organization science, marketing and management information systems). So it is not surprising that there is an overload of words which describe IO (e.g. Information flood, information smog, sensory overload, information explosion, cognitive overload, information load, information glut, knowledge overload, information fatigue syndrome, data overload, data explosion, cognitive load, etc.). Within the current publications of the last years the term IO prevail, but without ousting the other ones. Because of the immense number of existing terms and publications and included definitions, it is complicated to define the term IO properly. Edmunds and Morris [2000, p. 18] described in one of the first extensively literature review about IO, that there is no universal definition in spite of all publications. This is reasoned in the fact that IO can describe different situations, for example an accumulation of information which can't be processes because of the limited possibilities of the human brain. An opposite meaning would have an excessive amount of information of which just small amounts are relevant. The term contains negative aspects for individuals and/ or organizations. One of the first general definitions was established by Milford et al. [1977, p. 131]: "Information overload occurs when the amount of input to a system exceeds its processing capacity."

This classic definition was then expanded by Tushman and Nadler [1977, p. 615] and explained in this formula: information processing requirements (IPR) > information processing capacities (IPC). The two terms can be explained as follows:

Information processing capacity: Individual information processing can be characterized by individual aspects (such as: willingness, acceptance, motivation, knowledge, relevance, etc.)The core question is: How large is the individual cognitive capacity?

Information processing requirements: Information processing can also be characterized by non-individual aspects (such as: presentation format, access, completeness, number of options, time pressure, etc.). The core question is: How much capacity is needed to solve the problem / make a decision?

Thereby the terms requirement and capacity can be measured in available time [Eppler and Mengis 2004, p. 326]. IO therefore indicates a capacity and requirement problem as well as a time problem. Therefore this paper subsequently refers also to the definition of Bork [1994, p. 59]: "IO exists, if the given time under consideration of the systems period capacity, does not last out to process the accruing information properly during the decision making process/ task completion." This definition offers consciously a range, because the exact moment on which IO occurs is hardly to determine. The transition from underload to overload is fluent because the dysfunctional effect increases continuously [Bork 1994, p. 59].

\subsection{Causes of Information Overload}

Several frameworks which handle the different causes of IO have been developed (Schick et al. 1990, Bork 1994, Kock 2000, Gwizdka 2004, Allen et al. 2005, etc.). Two are well recognised. Moser et al. [2002] and Eppler and Mengis [2002].

Moser et al. [2002, appendix I] categorize the causes of IO into two main areas: barriers and overextension. Barriers are understood as external influence factors that handicap the processing of information (e.g. the amount of information). Overextensions are the effects of IO which result in qualitative bad or too much information.

Eppler and Mengis [2004, p. 330] relates IO at organizational and interpersonal level to five different causes (organizational design, person, task and processes, information and IT). In combination with the above mentioned approach of Tushmann and Nadler [1977, p. 615] figure 1 shows a conceptual model that integrates personal and organizational factors affecting Information Overload and Underload.

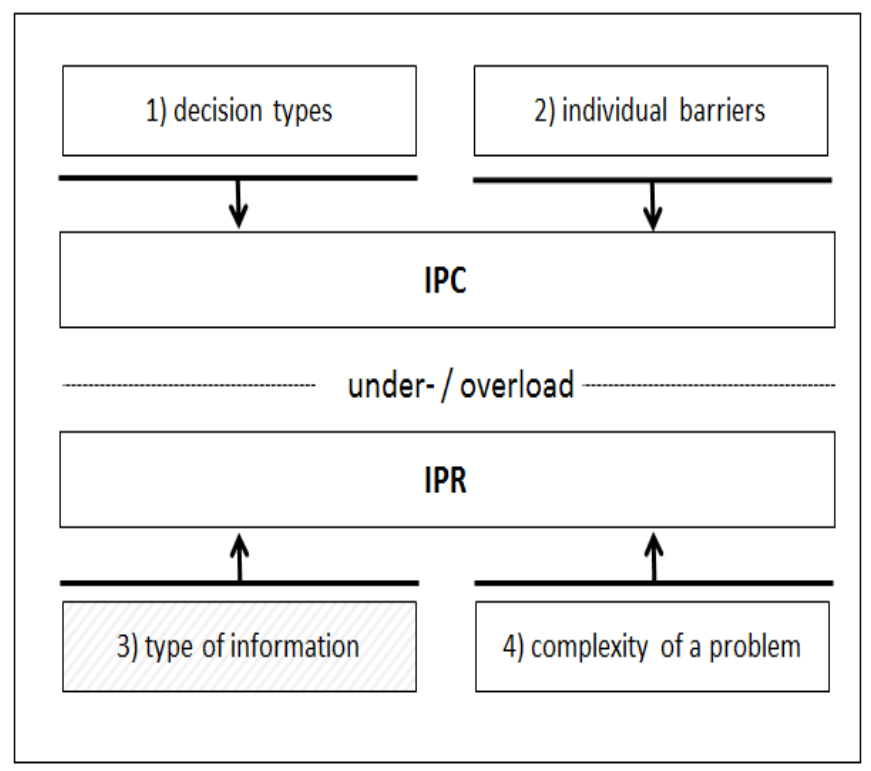

Fig 1: research framework

Tushmann and Nadler [1977, p. 615] compare the individual information processing capacity (IPC) - or as Allen et al. [2005, p. 5] call it: information behaviour - with the information processing requirements (IPR). As soon as the IPR is bigger than the IPC, IO accrues. IPR and IPC are two 
often used terms, but of course they are collective dimensions consisting of several variables which influence the under- / overload phenomenon. Two of the dimensions (3. and 4. of IPR in Figure 1) are heavily influenced by Jungermann et al. [2005, p. 123] as well as Förster-Trallo [2011, p. 17]. They divide the dimensions on the organizational side (IPR) in the complexity of a problem and the amount and type of information. Compared with this, Hecker [1998, p. 31] and Hausschildt [1983, p. 236] explain the decision types (1.) respectively individual barriers (2.). For the information processing requirement, IPC it is not only important how complex a problem is, but also how much information about the problem exists and the condition of the information. Several authors [Bork 1994; Hecker 1998, Shenk 1998; Davenport 1999; Edmunds et al. 2000; Moser et al. 2002; Gartner 2009; Hilpert et al. 2011] have previously highlightedhow the information amount grew rapidly, They also showed the imbalance between the information explosion and the dearth of information. The advantage of this conceptual framework captures several elements. Not only the added dimensions based on the well accepted definition of IPR and IPC are useful for crosssectional research, but also the expandability of the framework is assumed to be useful and stimulating for other researchers. Moreover the framework delivers many interesting research approaches as shown explained in the methodology.

\section{METHODOLOGY}

The developed framework was used to analyse the influence of bad and (ir)relevant information on the IO phenomenon through a case study research in four different companies. Furthermore a pilot study and a pre-test were conducted.

\subsection{Sample and Data Collection}

As mentioned above a case study approach was used to collect the needed data. The advantage of this research strategy is that it entails empirical investigation of the complex IO topic [Thomas, 2004 and Saunders et al., 2007]. Consequently quantitative (structured interview) as well as qualitative data (open interview and observation) were collected. To have the possibility to compare the results and find similarities and differences between the cases, a multiple case study strategy (with four cases) was chosen. For this reason Yin [2003] argues that multiple case studies are preferable to single ones.

Within the four case companies the research focus was on management accounting departments as a place for information workers. Across the cases 20 management accountants participated. They ranged in age from 29 to 55 , with the median age being 34.5. The median job experience was 7 years. Respondents were more likely to be male $(85 \%)$ and all have an academic background. The participants worked an average of 8.4 hours a day and used thereof 7.7 hours ICT. The most important communication channels for the management accountants are email, f2f meetings (informal and formal) and databases.
The collected data were analysed with the objective of establishing links between the type of information and perceived IO. This was achieved by the calculation of both descriptive statistics for each of the measurement items, and the Pearson correlation coefficient. The data were analysed by SPSS and MS Excel.

\subsection{Measures}

To test the influence of the type of information on the IO phenomenon the participants were asked and observed regarding the following topics. The used items during the quantitative part of the analysis are influenced by the work of Moser et al. [2000]. An overview of the inter scale correlation is shown in table 1. As explained above the study also contains qualitative results which also can be assigned to the following topics.

Bad information: Within this potential IO influence factor, the quality of information on the work place was analysed. A scale with 12 items was used to analyse the qualitative problems of information. A high value means that a participant receives a lot of information which are not useful because of their quality. The internal consistency of the scale is Alpha 0.82 .

Irrelevant information: Main objective of this topic is to find out how many irrelevant information the management accountants receive. A scale with 6 items focuses most of all on the important communication channel email. A high value means that a participant receives a lot of information which are not useful because of irrelevance. The internal consistency of the scale is Alpha 0.78.

Relevant information: This topic analyses how useful incoming information is and if management accountants can't ignore information. A scale with 9 items handles the important and relevant information and further more if different versions and sources of information exist. A high value means that a participant receives a lot of information which are important and useful. The internal consistency of the scale is Alpha 0.83 .

Others: Participants were also asked and observed about the nature of their work, communication behaviour, ICT trainings, ICT competence, ICT equipment and demographics. Furthermore the management accountants were asked about IO. 
Table 1: Descriptive statistics for measurement factors

\begin{tabular}{lcccccc}
\hline & $\mathrm{Bl}$ & $\|$ & $\mathrm{Rl}$ & items & mean & SD \\
\hline (BI) bad information & $(.82)$ & & & 12 & 36,9 & 6,7 \\
(II) irrelevant information &, 19 & $(.78)$ & & 6 & 17,0 & 5,4 \\
(RI) relevant information &, $\mathbf{4 0}$ &, $\mathbf{5 0 ^ { * }}$ & $(.83)$ & 9 & 31,4 & 6,0 \\
\hline
\end{tabular}

Pearson coefficients; $\mathrm{N}=20$; ${ }^{*} \mathrm{P}<0.05,{ }^{* *} \mathrm{P}<0.01$; in brackets Cronbachs Alpha

\section{FINDINGS}

As shown in table one two of the three scales, related to the mentioned topics, show an inter-correlative connection. This includes the scale relevant information with bad information and irrelevant information. This is probably reasoned in the same basis of the scales, the amount of information. Surprisingly the scale irrelevant information shows no correlation with bad information. More important for this study is the connection between the topics and the IO phenomenon. The correlation coefficients in table two measure the relationship between the different impact- factors to the IO phenomenon. The results are presented for the four case companies and a cross case analysis (the analysis for all participants). The analysis show a correlation for bad information within the cross case analysis (0.43). More detailed this positive correlation can also been found in case I, case II and case IV. Furthermore a correlation of relevant information within case I and case IV can be identified. Apart from the two scales, there is no relation of irrelevant information with IO which is probably based on the items in the scale.

Table 2: Correlation between Information Overload (IO) and bad-, (ir)relevant information

\begin{tabular}{lccccc}
\hline & $\begin{array}{c}\text { cross case } \\
(\mathrm{IO})\end{array}$ & $\begin{array}{c}\text { case I } \\
(\mathrm{IO})\end{array}$ & $\begin{array}{c}\text { case II } \\
(\mathrm{IO})\end{array}$ & $\begin{array}{c}\text { case III } \\
(\mathrm{IO})\end{array}$ & $\begin{array}{c}\text { case IV } \\
(\mathrm{IO})\end{array}$ \\
\hline 1 bad informatio & $\mathbf{4 3 ^ { * }}$ & $\mathbf{, 8 5 ^ { * }}$ & $\mathbf{, 8 7 ^ { * }}$ &,- 03 & $\mathbf{8 6}^{*}$ \\
2 irrelavant information &, 24 &,- 54 &, 39 &,- 08 &, 71 \\
3 relevant information &, 31 & $\mathbf{, 8 2}^{*}$ &, 73 &,- 44 & $\mathbf{9 2}^{*}$ \\
\hline
\end{tabular}

Pearson coefficients; $\mathrm{N}=20 ;{ }^{*} \mathrm{P}<0.05$

In addition to the presented scales the participants were asked: "How has the proportion of relevant information changed with regard to the total volume of information in the past 5 years?" This question investigates if the management accountants think that within a growing information amount the relevant information relatively increased or decreased. The result is displayed in figure two.
$30 \%$ of the participants answered that today 'less' or 'much less' relevant information are available, on the other hand $50 \%$ answered that there are 'more' or 'much more' relevant information available for them. This show how most of the participants think that the amount of relevant information increased over the last five years.

\title{
How has the proportion of relevant information changed with regard
} to the total volume of information in the past 5 years?

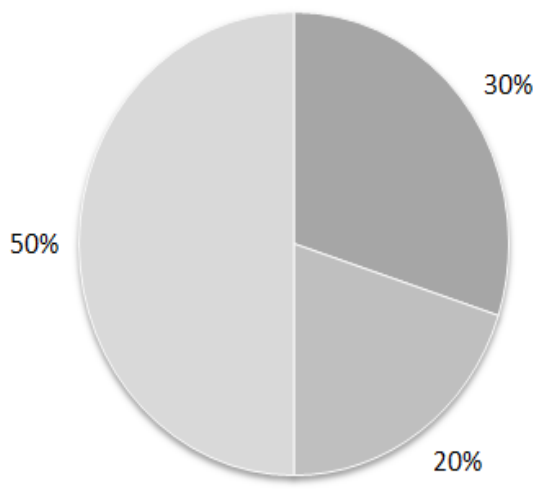

\author{
less and much less \\ relevant information \\ same proportion \\ more and much \\ more relevant \\ information
}

Fig 2: proportion change of relevant information in the last five years 
This result leads to the question "what makes information relevant/ important. With the help of the infinity diagram technique different clusters were identified. Thereby just topics with more than three answers are shown in figure three. The management accountants answered that relevant information can be used to solve a problem.

Information is important/ relevant if:

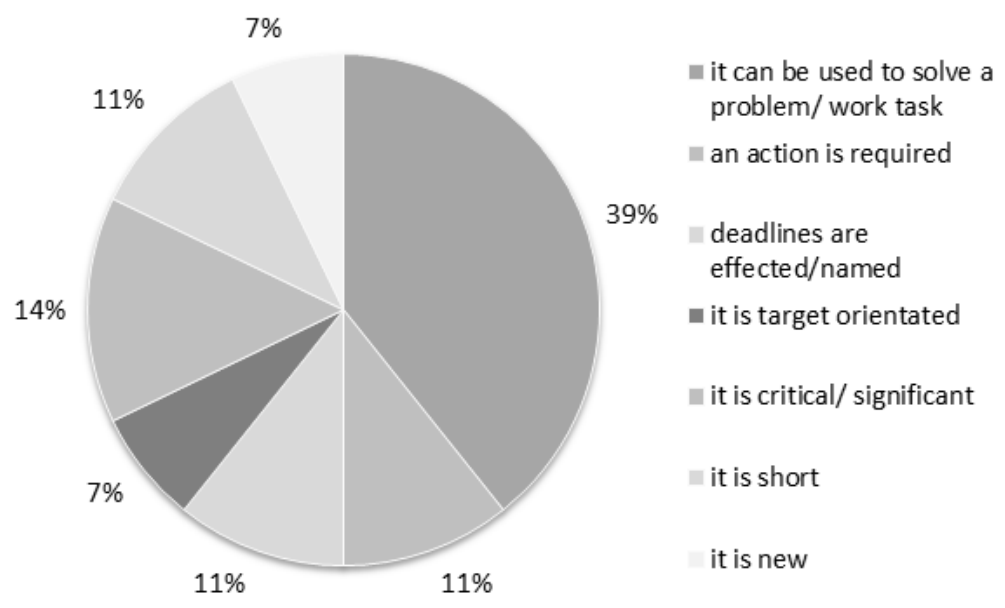

Fig 3: Attributes of relevant information

\section{DISCUSSION AND CONCLUSIONS}

This study of the information type impact on the IO phenomenon is based on a sample of 20 management accountants with a relatively young age, well-educated which have a high experience with the modern communication channels. The section findings suggest positive similarities to previous research around the topic of information type [Moser et al. 2002]. The findings show meaningful connections. A correlation between IO with bad information and partly with relevant information can be detected. On the other hand no correlation with irrelevant information can be noticed. The research data supports the conclusion that there is a relationship between IO and the information type.

To forecast the behaviour of individuals and organizations it is essential to understand the changes to both IPC and IPR. That means also the type of information and therefore bad and (ir)relevant information. With a deeper understanding on these dimensions it is possible to manage the future information flow. This in turn could help to optimize the balance between too less and too much information. Consequently the information flow could be improved and effective countermeasures can be established. This results in a decreasing stress-level for humans and cut costs for organizations. This study provides the findings based on a relatively small sample base. Thus, a suggestion for future research is to increase the sample size.

\section{REFERENCES}

[1] Allen, D.K.; Shoard, M. (2005): Spreading the load: mobile information and communications technologies and their effect on information overload. The University of Leeds
[2] Baumöl, U. (2008): Change Management in Organisationen Situative Methodenkonstruktion für flexible Veränderungsprozesse (Change management in organizations - Situational methods for flexible change management). Gabler Verlag Wiesbaden

[3] Bork, T. (1994): Informationsüberlastung in der Unternehmung (Information Overload in organizations). Peter Lang Verlag, Frankfurt am Main

[4] Bouwman, H.; Hoof, B. v. d.; Wijngaert, L v. d.; Dijk, J. v. (2005): Information \& Communication Technology in Organizations, Sage London

[5] Davenport, T. (1999): Human Capital. Jossey-Bass

[6] Davenport, T. (2005): Thinking for a living: how to get better performance and results from Knowledge Workers. HBS Press Boston

[7] Dietze, A. (2003): Information system value management. Gabler Verlag, Vallendar

[8] Diller, H. (1975): Produkt-Management und Marketing-Informationssysteme (Product management and marketing information systems). Duncker \& Humblot, Berlin

[9] Doppler, K.; Lauterburg C. (2000): Change Management. ). Auflage Campus Verlag, Frankfurt/ Main

[10] Dryer, D.C.; Eisbach, C. ; Ark, W.S. (1999): At what cost pervasive? A social computing view on mobile computing systems. IBM Systems Journal, 38(4)

[11] Edmunds, A.; Morris, A. (2000): The problem of information Overload in business organisations: a review of the literature. International Journal of Information Management 20

[12] Eppler, M. J.; Mengis, J. (2004): The concept of information overload: a review of literature from organization science, accounting, marketing, MIS 
and related disciplines. Tayler \& Francis Lugano

[13] Farhoomand, A.; Drury, D. (2002): Managerial Information Overload, Communication of the ACM (Nr. 45/10), New York

[14] Förster-Trallo, D. (2009): Einfluss von Stress auf die Entscheidungsfähigkeit von Führungskräften in dynamischen Märkten (Influence of stress on the ability of managers to make decisions in dynamic markets). Berlin

[15] Gartner (2009): Gartner Says Worldwide IT Services Revenue Declined 5.3

[16] Percent in 2009. Stamford

[17] Gwizdka, J. (2004): Email Task Management Styles: The Cleaners and the Keepers. CHI 2004, Vienna

[18] Hausschildt, J. (1983): Die Effizienz von Führungsentscheidungen und ihre Ursachen (Causes of efficiency by leader's decision making). Tübingen

[19] Hecker, M. (1998): Informationsüberflutung und deren Vermeidung (Information Overload and their avoidance). Verlag Dr. Kovac, Hamburg

[20] Hilbert, M.; López, P. (2011): The World ' s Technological Capacity to Store, Communicate, and Compute Information. VOL 332 SCIENCE

[21] Jungermann, H.; Pfister, H.-R.; Fischer, K. (2005): Die Psychologie der Entscheidung (The psychology of decision making). 2nd edition, Elsevier, Spektrum, Akad.-Verlag, Heidelberg

[22] Katzer, J.; Fletcher P. (1996): The information environment of managers. Neal-Schuman, New York

[23] Kock, N. (2000): Information Overload and Worker Performance: A Process-Centered View. Knowledge and Process Management Volume 7 Number 4

[24] Kulke, U. (2007): In den Klauen der Zeitfresser (The claw of time eating), Die Welt, Berlin

[25] Milford, J.T.; Perry, R.P. (1977): A methodological study of overload. Journal of General Psychology

[26] Miller, G. A. (1963): The magical number seven, plus or minus two: some limits on our capacity for processing information. Mathematical Psychology Vol. I, New York

[27] Moser, K.; Preising, K.; Göritz, A. S.; Paul, K. (2002): Steigende Informationsflut am Arbeitsplatz: belastungsgünstiger Umgang mit elektronischen Medien (The rising flood of: How to handle ICT). Schriftenreihe der Bundesanstalt für Arbeitsschutz und Arbeitsmedizin, Dortmund/Berlin/Dresden

[28] Peavler, W. S. (2007): Pupil Size, Information Overload, and Performance Differences Psychophysiology (Volume 11 Issue 5)

[29] Saunders, M., Lewis, P.; Thornhill, A. (2007): Research methods for business students. Pearson Education Ltd., Essex

[30] Schick, A. G.; Gorden, L. A..; Haka, S. (1990): Information overload: A temporal approach. Accounting Organizations and Society 15:199-220.

[31] Shenk, D. (1998): Infosmog. Lichtenberg Verlag, München

[32] Thomas, A. B. (2004): Research skills for management studies, Routledge London
[33] Tushman, M. L.; Nadler D. A. (1978): Information processing as an integrating concept in organizational design. Academy of management review 3: 613 - 625

[34] Wingens, S. (2007): Informationsverschmutzung (Information pollution). VDM Verlag Dr. Müller, Saarbrücken

[35] Yin, R. K. (2003): Case Study Research. Design and Methods. $3^{\text {rd }}$ edition, Sage Publications, London

[36] Zeldes, N. (2007): The impact of Information Overload. Online available: http://firstmonday.org/htbin/cgiwrap/bin/ojs/index.ph $\mathrm{p} / \mathrm{fm} /$ issue/view/251 [Accessed 23.11.2011] 